\title{
Narrativas audiovisuais ensinando História do Brasil na Era Vargas: filme Os Inconfidentes, produzido pelo Instituto Nacional do Cinema Educativo (INCE)
}

\author{
Lara Rodrigues Pereira ${ }^{1}$
}

Resumo: o presente artigo é recorte de pesquisa de doutorado, em andamento, pelo Programa de Pós-Graduação em Educação (PPGE) cursado na Universidade Federal de Santa Catarina (UFSC), cujo mote é a investigação da apropriação de personagens e eventos históricos por filmes do Instituto Nacional do Cinema Educativo (INCE), com o intuito de ensinar História do Brasil. Neste texto, especificamente, me debruço sobre o filme $O s$ Inconfidentes, que trata da repatriação dos restos mortais de participantes da inconfidência mineira (que receberam o degredo como forma de punição pela insurgência) e que mais de um século depois foram recebidos com honras pelo Estado brasileiro, representado pela figura do então presidente Getúlio Vargas.

Palavras chave: Estado Novo, Ensino de História, Os Inconfidentes

Abstract: This article is part of a PHD research (in progress), by the Post-Graduation Program in Education (PPGE), at the Federal University of Santa Catarina (UFSC), and it intends to investigate the appropriation of characters and historical events by films made by the National Institute of Educative Cinema (INCE), whose purpose was to teach Brazilian History. In the text, specifically, I analyze the film " $O s$ Inconfidentes", which portrays the repatriation of the remains of the members of the "Inconfidencia Mineira" (people who were expelled as a punishment of the uprising) and that, more than one century later,

Graduada e Mestra em História, doutoranda do Programa de Pós-Graduação em Educação pela Universidade Federal de Santa Catarina (PPGE-UFSC), linha de pesquisa Sociologia e História da Educação. Bolsista CAPES, e-mail: lararp81@gmail.com. 
were received with great honor by the Brazilian State, represented by the then president Getúlio Vargas.

Keywords: Estado Novo, Teaching History, The Inconfidentes.

\section{Introdução}

Em 04 de dezembro de 1937, na praia do Russel, Rio de Janeiro, Getúlio Vargas participou da cerimônia de queima das bandeiras estaduais e hasteamento da bandeira nacional. Seu discurso, no âmbito do Estado Novo, trazia apelo pela unidade em torno da nação: "Abolimos as bandeiras e escudos estaduais e municipais, os hinos regionais e os partidos políticos. Tudo isso se fez visando consolidar a unidade política e social do país."2 O Estado Novo (19371945) é conhecido como um período de plenos poderes conferidos ao chefe do executivo, sob o pretexto da garantia de segurança e união nacionais. Para consolidar tais intenções lançou-se mão da propaganda pelos meios de comunicação, por meio de estratégias educativas e da produção cultural. Nessa conjuntura, de modo específico, no fim de 1936 foi criado o Instituto Nacional do Cinema Educativo (INCE), que apesar de ter sido inaugurado meses antes da instituição do Estado Novo, serviu a ele sendo também fruto daquele contexto político. Embora existam vozes contrárias de alguns estudiosos, como Fernão

${ }^{2}$ Disponível em: <https://www.youtube.com/watch?v=xKoh2n1OTo4>. Acesso em: 13 ago. 2015. 
Pessoa Ramos, afirmando que o INCE "possuiu, durante o Estado Novo, um espaço de manobra bastante razoável, desvinculado das necessidades mais estreitas da propaganda política" (RAMOS, 2004, p. 159), no caso de Inconfidentes (assim como em outros documentários do referido Instituto) percebe-se a intenção de reverenciar o chefe da nação apresentando sua relação de respeito com o passado de luta dos Inconfidentes. É possível perceber a tentativa de alinhá-lo àquela lógica de contestação representada pela inconfidência, pois ele mesmo, anos antes, insurgiu-se contra os gestores da nação na Revolução de 1930 (embora dialogasse de maneira muito estreita com o "antigo regime" e também fizesse parte daquela complexa estrutura política). Mas a afirmação de Ramos, citada acima, precisa ser considerada levando em conta as tensões existentes entre os ministérios varguistas. É sabido que Capanema esforçou-se para manter o INCE sob os auspícios do Ministério da Educação e Saúde, resistindo às investidas do Departamento de Imprensa e Propaganda, conforme trecho a seguir:

Em 1938, Capanema reivindicou, contrariando as pretensões do Ministro da Justiça Francisco Campos, que tanto o serviço de radiodifusão Educativa como o Instituto Nacional do Cinema Educativo permanecessem como área de atuação do Ministério da Educação.(CAPELATO, 2008, p. 81).

O período que compreende a inauguração do INCE e o fim do Estado Novo foi pródigo na produção de filmes sobre História do Brasil, não em termos quantitativos, mas privilegiando narrativas que contemplavam o que, na época, entendia-se ser importante para o 
ensino de História: destaque de grandes personalidades e eventos históricos,que, naquela leitura, de uma forma ou de outra, contribuíram para a pujança da nação.Estabeleço esta pesquisa tendo por base o documentário Inconfidentes ${ }^{3}$,observando que o Estado Novorepresentou, de acordo com Angela de Castro Gomes (2013) e Maria Helena Rolim Capelatto (2009), dentre outros pesquisadores,um período de intenso investimento nos processos de construção de identidade nacional, com ênfase para ações ligadas à educação.

De acordo com Cristina Souza da Rosa (2006), durante o Estado Novo a educação foi vista como o principal instrumento para a criação do que se entendia "o novo homem nacional", citando discursos de Vargas e do Ministro Capanema que invocavam este termo. Para além da ordem do discurso, podemos perceber tais iniciativas concretizadas por meio da criação de várias Escolas técnicas, além do investimento na padronização dos processos educacionais dado pelas reformas orquestradas pelo Ministério.

Já no início da gestão Vargas, em 1931, o Ministério da Educação, sob a direção de Francisco Campos, instituiu a primeira reforma após a revolução da 1930, e Rosa (2006) salienta que a reorganização do currículo de História trazia a prerrogativa de formar o indivíduo para a cidadania por intermédio do que reconheceu como nova metodologia: associando a História episódica à biografia de grandes vultos. Esta "nova” metodologia já era amplamente utilizada há

${ }^{3}$ OS INCONFIDENTES, 1936. Direção: Humberto Mauro, INCE, Brasil. 
décadas, haja vista os compêndios de História do Brasil assinados por José Inácio de Abreu e Lima, de 1843, analisados por Selma Rinaldi de Mattos em tese de 2007, entre outros. Mas, se a referida metodologia já era usada em compêndios para a concretização do ensino de História, pode-se afirmar que, com o advento da reforma Campos, houve padronização e ampla difusão de estratégias educacionais (que abarcavam o tal método), com alcance nacional sem precedentes.

A metodologia de unir a História episódica a biografias de grandes vultos será a tônica das produções concernentes à História do Brasil feitas pelo INCE. Nelas, além disso, teremos outro aspecto recorrente em tantos filmes do Instituto que versavam sobre outras áreas do conhecimento: a preocupação com o caráter científico das narrativas. Para tanto havia normalmente a legitimação da cientificidade dos filmes dada pela chancela de um especialista. No caso de Inconfidentes isso fica explícito pela menção ao discurso do historiador e membro da Academia Brasileira de Letras, Pedro Calmon. A construção dos filmes do INCE foi perpassada por múltiplas intencionalidades: propaganda política, disseminação artística, formação do cidadão tendo em vista os considerados bons exemplos do passado, cientificismo, sendo que todos estes aspectos serviam ao propósito maior de educar os brasileiros para aquele "novo" Brasil em curso. 


\title{
Em cena: Os Inconfidentes
}

Em dezembro de 1936, o INCE produziu um documentário, dirigido pelo cineasta Humberto Mauro, que tinha por objetivo divulgar:

\begin{abstract}
A chegada à capital da República dos restos mortais de treze inconfidentes mineiros. No cais do porto, o presidente Getúlio Vargas e autoridades acompanham o desembarque das urnas do navio Bagé. Diante do pavilhão do Touring Club do Brasil, autoridades observam a transferência das urnas para os caminhões do Exército. ${ }^{4}$
\end{abstract}

Inconfidentes conta com duração aproximada de seis minutos e, ao contrário do que sugere o título, seu protagonismo não é exclusivo dos finados repatriados ou do "líder" insurgente Tiradentes, mas sim dividido com Getúlio Vargas, então presidente, em caráter provisório, do Brasil. Podemos, a título de análise, dividir o referido documentário em duas partes: a primeira que conta a cerimônia de repatriação dos restos mortais dos degredados recebidos pelo presidente Vargas, outras autoridades e pela população. Já a segunda etapa privilegia um apanhado histórico sobre a figura de Tiradentes e sua liderança frente ao levante, tendo por base alguns elementos de acervo material disponíveis

\footnotetext{
${ }^{4}$ Disponível em: http://www.bcc.org.br/filme/detalhe/008166. Acesso em: 13 ago. 2015.Este é trecho da sinopse do documentário produzido pelo INCE, disponível para consulta na página acima.
} 
em museus mineiros: objetos pessoais, a casa de encontro dos inconfidentes e representações da figura de Tiradentes em quadros. Os documentários do INCE eram normalmente narrados, sendo que havia a preocupação de abri-los com créditos que indicavam direção, produção, responsável(is) técnicos pela consultoria (quando existia), título, além de legenda que servia para introduzir o tema, contextualizando-o. Após este "sumário" audiovisual, normalmente as imagens apresentadas eram traduzidas por meio de narração que acompanhava a trama do início ao fim.

A seguir transcrevi o teor da narração do documentário Inconfidentes com o intuito de compreender as estratégias adotadas pelo INCE para apresentar os dois momentos históricos invocados na produção: 1936 e 1792. As passagens em negrito foram introduzidas por mim com o intuito de contextualizar a leitura da narração alinhando-a à imagem e outros recursos trazidos pelo filme.

Ato I:

"Por iniciativa do Ministério da Educação e Saúde Pública, foi efetuada a trasladação dos restos mortais de treze dos inconfidentes mineiros condenados ao degredo perpétuo pouco após o insucesso da Inconfidência de Vila Rica. Abordo do Bagé, aportaram à nossa capital, precedentes de Lisboa, as urnas contendo os restos mortais dos mártires brasileiros tendo então a cerimônia iniciada com a visita a bordo do senhor doutor Getúlio Vargas, presidente da República, doutor Gustavo Capanema, ministro da Educação e demais autoridades. O corpo oficial, feita a visita ao Bagé, encaminhou-se para o pavilhão do Touring Club do Brasil, onde aguardou 
a chegada das urnas transferidas para as carretas do exército. À chegada dos coches militares discursaram o senhor Negrão de Lima, representante de Minas Gerais, e Pedro Calmon, Historiador e membro da Academia Brasileira de Letras. Em seguida foi organizado o cortejo sob as salvas de tiro, atravessando a avenida em direção à catedral metropolitana. A cerimônia frente ao templo foi assistida por grande massa popular, tendo nessa ocasião os sinos da matriz de São José oferecido raro espetáculo da execução do hino nacional. Em seguida foram as urnas depositadas na capela Nosso Senhor dos Passos, dependência histórica da catedral, ficando expostas para a visitação pública as urnas dos Inconfidentes mineiros: Francisco de Paula de Andrade, Domingos de Abreu Vieira, Salvador Carvalho do Amaral Gurgel, Ignácio José de Alvarenga Peixoto, Luiz Vaz de Toledo Pisa, José Alves Maciel, José Aires Gomes, João da Costa Rodrigues, Francisco Antonio de Oliveira Lopes, ThomásAntonio Gonzaga, Antonio de Oliveira Lopes, Victorino Gonçalves Veloso, Vicente Vieira da Motta.

\section{Ato II:}

\section{(troca de cenário, agora o filme passa-se em Minas Gerais)}

A figura histórica da maior vítima da Inconfidência Mineira, o alferes José Joaquim da Silva Xavier, alcunhado Tiradentes. Este é um retrato, feito por João Batista em 1885, tendo pertencido ao Clube Tiradentes(ao som do Hino Nacional). Ouro Preto cultiva a memória histórica de Tiradentes, seu grande filho, lá se acham os mais belos monumentos representando a figura do mártir e lá também a casa onde se reuniam os inconfidentes. Traves da forca onde foi executado Tiradentes, a 21 de abril de 1792, 
banco da sala da Casa dos Contos em Ouro Preto, onde foram julgados os réus da Inconfidência, caçamba de montaria usada pelo alferes José Joaquim da Silva Xavier, Tiradentes, O precursor, vestimenta da Alma, o quadro a óleo de Pedro Bruno, representando os últimos dias de Tiradentes na prisão, pouco antes de ir para a forca, a bandeira utilizada e idealizada pelos Inconfidentes com a divisa histórica libertas quae será tamen. ${ }^{5}$

No primeiro ato há a explicação do que seria a cerimônia registrada no filme, com ênfase para a "iniciativa do Ministério da Educação e Saúde Pública" por meio do qual os restos dos inconfidentes puderam ser repatriados, marcando que aquela era uma questão educacional, sobretudo. A figura do "senhor doutor Getúlio Vargas" é apresentada desta forma com o intuito de destacar a solenidade do evento e também do chefe da nação que, com a ajuda de seu staff, da Igreja católica, do exército e dos populares (massa, conforme a narração), corrigiu uma injustiça histórica, resgatando as cinzas dos inconfidentes, concedendo-lhes o descanso eterno em terras brasileiras. E a câmera busca por ele; mesmo em um documentário curto e dividido em duas etapas é preciso perceber o destaque dado à figura de Vargas.

Cerimônias como aquela eram importantes para potencializar a imagem do chefe da nação (ainda que em caráter provisório) junto aos jovens, que viriam a assistir ao documentário, dando-lhes uma ideia de passado comum a todos os brasileiros. Este tipo de estratégia era

\footnotetext{
${ }^{5}$ Narração, na íntegra, do documentário do INCE Inconfidentes.
} 
recorrente nos filmes do INCE, em títulos como Barão do Rio Branco, $O$ despertar da redentora (em homenagem à Princesa Isabel) e Bandeirantes. Percebe-se que a História do Brasil era privilegiada, pois havia a necessidade de conhecê-la para após sentir-se pertencente a ela; tal lógica é reforçada pela inexistência de filmes do INCE, durante o Estado Novo, que versassem sobre a História Universal. De acordo com Capelato (2008, p. 233):

A ênfase na unidade nacional constituía elemento chave na configuração da nova identidade nacional coletiva.Na década de 1930 houve um debate entre os defensores de uma visão "universalista" do ensino de História, posta em prática a partir da introdução da "História da Civilização" na grade curricular. Contra a perspectiva universalista, manifestaram-se os defensores da "singularidade nacional", que também defendiam a ideia de que o porvir encontrava-se no passado e baseava-se na tradição. A defesa do ensino da História Pátria atrelava-se a uma concepção nacionalista que enfatiza a necessidade de formação da consciência nacional.

A ideia de que nas glórias do passado residem exemplos a serem seguidos para a pavimentação do presente e do futuro do país, conforme aponta Capelato, explica a escolha por promover a cerimônia em homenagem aos Inconfidentes e registrá-la por meio de documentário para ser assistido por um número ainda maior de jovens brasileiros.

No segundo ato, com a ação ambientada em Minas Gerais, a figura de Tiradentes é apresentada como líder martirizado, buscando 
referências materiais de sua existência, por meio de artefatos pertencentes a ele que resistiram ao tempo, para lembrar as gerações vindouras de sua importância. A maneira como a Inconfidência e seus participantes é representada é laudatória, convertendo-os em heróis nacionais. A revolta não é apresentada como uma insurgência regional motivada por questões econômicas e não identitárias ou culturais, e sim, nacional, motivada pela intenção da liberdade com relação à Metrópole. $\mathrm{O}$ fato das províncias pouco se comunicarem à época do ocorrido e que nem havia um sentido de identidade comum aos moradores das mais diferentes regiões da então colônia Brasil é convenientemente esquecido. Neste ponto recorro a Capelato novamente, pois o regionalismo inerente à Inconfidência Mineira cede espaço para o nacionalismo brasileiro do Estado Novo:

Na construção de uma moral nacional associada a uma memória histórica, eram negados, enfaticamente o regionalismo, ateísmo, os conflitos sociais e outras ideias consideradas prejudiciais. As medidas pretendiam controlar não só o passado, indicando como deveria ser representado, mas também o futuro, ao proibir qualquer afirmação ou sugestão que induzisse ao pessimismo; ao contrário, era esperado que se estimulasse o otimismo nos dias vindouros (CAPELATO, 2008, p. 233).

O nacionalismo aplacando regionalismos pode ser identificado nesta cerimônia (e seu registro cinematográfico), pois o sepultamento dos restos mortais dos próceres inconfidentes foi feito na capital federal brasileira e não em Minas Gerais, além disso, sua trajetória de luta é 
traduzida como a luta de uma nação em busca da liberdade, e não de uma província em busca de menor carga tributária. O caráter otimista apontado pela autora pode ser visto no final do documentário, quando a câmera enfoca a bandeira dos Inconfidentes (depois usada pelo estado de Minas Gerais) ao som do Hino nacional brasileiro.

Outro aspecto chama atenção no documentário: o uso do hino nacional para embalar a ação. A escolha da trilha sonora foi, possivelmente, mais uma estratégia no intuito de abrasileirar a revolta colonial, tornando-a nacional e contemporânea. A seguir descrevo as passagens em que o hino é destacado, tentando compreender tal escolha e seus desdobramentos para a concretização do documentário.

\section{O uso do Hino Nacional em Os Inconfidentes}

Em Os Inconfidentes o hino nacional aparece em dois momentos. No primeiro não se pode ouvi-lo nitidamente, é citado pelo narrador quando afirma: "A cerimônia frente ao templo foi assistida por grande massa popular, tendo nessa ocasião os sinos da matriz de São José oferecido raro espetáculo da execução do hino nacional". Os restos mortais saudados pelas autoridades e populares foram recepcionados na igreja ao som do Hino brasileiro, demonstrando um caráter religioso e cívico naquela saudação, recorrente em outras cerimônias típicas do Estado Novo, tal qual a da queima das bandeiras estaduais em 1937, citada no início deste texto. 
A câmera se volta para cada uma das treze urnas e neste momento o volume do som dos sinos, que até então ouvia-se em segundo plano, passa a ficar mais alto, dando à cerimônia um requinte de patriotismo religioso. Este recurso pode ser considerado, à guisa do que apregoa Jean Cocteau, um aprofundamento da sensação dada pelo filme: "Não vamos ao cinema para ouvir a música. Queremos que ela aprofunde em nós uma impressão visual. Não lhe pedimos que nos explique as imagens.” (MARTIN, 2013, p. 138).

Para Marcel Martin (2013), estudioso da linguagem cinematográfica, a música é um importante instrumento que teria a prerrogativa de traduzir as imagens ou salientá-las e, em alguns casos, até desvirtuá-las:

A música é, portanto um elemento particularmente específico da arte do filme, e não é de surpreender que desempenhe um papel tão importante e às vezes pernicioso: "Em certos casos, a significação literal das imagens resulta ser extremamente tênue. A sensação torna-se musical; a tal ponto que, quando a música a acompanha, de fato, a imagem obtém da música o melhor de sua expressão ou, mais precisamente, de sua sugestão. (MARTIN, 2013, p. 136).

A sugestão passada pelas músicas nos filmes, indicada pelo autor no fragmento acima, pode ser vista em Os Inconfidentes quando do uso do hino nacional, para imprimir vigor cívico, mas também caráter sagrado à cerimônia representada. Os inconfidentes são reconhecidos como âncoras da nação (por isso saudados com o hino 
nacional), pois, de acordo com o que sugere o filme, ousaram sonhar com uma autonomia que só chegou a se concretizar anos depois. $\mathrm{O}$ fato daquele movimento ter sido motivado, sobretudo, pelos altos impostos cobrados pela coroa portuguesa (sem caráter propriamente popular, portanto) e que muitos dos inconfidentes não queriam o rompimento com a metrópole não é mencionado.

O caráter narrativo desempenhado pela música, de acordo com Martin (2013) é expressado também no ato II de Inconfidentes, quando a ação se passa nos centros históricos marcados pela insurgência, em Minas Gerais. A transição entre os dois atos do documentário é marcada pela apresentação de uma imagem de Tiradentes, de longos cabelos e barba, vestindo o que parece uma túnica branca (à Jesus Cristo) com uma corda no pescoço. Em um primeiro momento as badaladas dos sinos acompanham o narrador quando afirma "A figura Histórica da maior vítima da Inconfidência Mineira". Neste ponto, a associação da imagem do mártir (tendo a corda de seu iminente enforcamento já no pescoço) com a sacralidade invocada pelos sinos, somadas à ênfase dada pelo narrador à palavra vítima, dão um tom de messianismo à figura de Tiradentes, o cordeiro que foi sacrificado pela nação. Logo em seguida, na continuação da fala do narrador: "o alferes José Joaquim da Silva Xavier, alcunhado Tiradentes", os sinos cessam, dando lugar ao hino nacional, que acompanhará imagem e narração até o fim do filme. 


\section{Considerações finais}

O ensino de História do Brasil tinha a prerrogativa de impingir nos jovens estudantes brasileiros conhecimento e, conforme aponta Capelato (2008), paixão por um passado homogêneo, virtuoso, repleto de bons exemplos, que vinha sendo editado e constantemente reescrito com a intenção de estimular a unidade nacional. Buscar na insurgência mineira essas características exigiu certo esforço do Ministério da Educação e Saúde, uma vez que houve a necessidade de tornar uma revolta colonial a efígie de uma insurgência em prol da unidade nacional, coisa que era perseguida, porém que ainda não era realidade na década de 1930, haja vista a revolução constitucionalista ocorrida dois anos antes do lançamento do filme educativo. $\mathrm{O}$ caráter fragmentário do Brasil, embora estivesse mais próximo da realidade do que a intenção de unidade, era suprimido por manobras sutis como o uso do hino nacional no documentário, sobretudo nas cenas passadas em Minas Gerais, transformando aquela história em nacional e não regional.

As disputas pelo INCE dadas no alto escalão varguista podem ser interpretadas como a tensão entre aqueles que tencionavam transformar a educação em propaganda política e aqueles que queriam certa autonomia. Neste embate, percebe-se que preservando o INCE sob a tutela da pasta da Educação, Capanema conseguiu tornar o órgão mais "científico" e menos panfletário, embora houvesse momentos como $O s$ 
Inconfidentes, em que a propaganda política alcançasse protagonismo em detrimento do caráter educacional puro e simples.

\section{Referências}

CAPELATO, Maria Helena Rolim. Multidões em Cena: Propaganda política no Varguismo e no Peronismo. 2. ed. São Paulo: UNESP, 2008.

FERRO, Marc. Cinema e História. Rio de Janeiro: Paz e Terra, 1992.

A Manipulação da História no Ensino e nos Meios de Comunicação. São Paulo: IBRASA, 2009.

GOMES, Angela de Castro. A invenção do trabalhismo. 3. ed. Rio de Janeiro: FGV, 2013.

LAGNY, Michelle. O cinema como fonte de História. In: NOVOA, Jorge (Org.).Cinematógrafo. São Paulo: UNESP, 2009, p. 99-132.

LANGER, Johnni. Metodologia para análise de estereótipos em filmes. História Hoje, São Paulo, v. 1, n. 5, p. 1-13, dez.2004. Acesso em: 12 jan. 2012.

MARTIN, Marcel. A linguagem cinematográfica. 2. ed. São Paulo: Brasiliense, 2013.

MATTOS, Selma Rinaldi. Para formar os brasileiros;o compêndio da História do Brasil de Abreu e Lima e a expansão para dentro do Império do Brasil. Tese (Doutorado em História Social) - USP, 2007.

RAMOS, Fernão Pessoa. Mauro Documentarista. Revista USP, São Paulo, n.63, p. 157-168, set./nov. 2004.

ROSA, Cristina Souza da. O ensino de História do Brasil através dos filmes educativos durante o Estado Novo.anais do XII Encontro Regional de História, ANPUH-RJ, 2006. 
Artigo recebido em 31/10/2015, aceito em 14/02/2016

Revista Vernáculo n. ${ }^{\circ} 38$ - segundo semestre /2016 ISSN 2317-4021 